\title{
The efficacy of intravenous clonidine premedication to reduce surgical area bleeding in posterior lumbar spine fusion surgery
}

\author{
Suresh Rajkumar', Senthil $\mathbf{M}^{2}$, Ezhilrajan $V^{3}$ \\ ${ }^{1}$ Dr. Suresh Rajkumar, MDAnaesthesiology, Assistant Professor. ${ }^{2}$ Dr. Senthil M, DA.(DNB)Anaesthesiology, Assistant \\ Professor. ${ }^{3}$ Dr. Ezhilrajan V, MD.DA.(DNB) Anaesthesiology, Associate Professor, Department of Anaesthesiology, All \\ are affiliated with Aarupadai Veedu Medical College, Puducherry, India.
}

Address for Correspondence: Dr. Suresh Rajkumar M.D. Email: drsureshrajkumar@rediffmail.com

\begin{abstract}
Background: A posterior lumbar spine fusion surgery always associated with significant amount of blood loss and requires blood transfusion. The purpose of this study is to evaluate the efficacy of intravenous clonidine premedication to achieve bloodless surgical field and decrease the need for blood transfusion by controlled hypotension. Methods: Sixty patients scheduled for posterior lumbar fusion surgery were included in this randomized placebo controlled trail. Patients were classified into two groups: Group 1 received intravenous clonidine $3 \mu \mathrm{g} / \mathrm{kg}$ by infusion over 15 minutes before surgery and Group 2 received placebo as same. Hemodynamic variables, quality of surgical field by bleeding severity score, estimated amount of blood loss, duration of surgery and any blood transfusion were analyzed. Results: Heart rate and mean arterial pressure found less in clonidine group than placebo but not significant. The estimated blood loss $\left(390.8 \pm 99.99 \mathrm{~mL}\right.$ vs $\left.741.13 \pm 79.90 \mathrm{~mL} ; \mathrm{P}=0.001^{*}\right)$ and duration of surgery $(160.67 \pm 16.91 \mathrm{vs} 205.9 \pm 16.72 \mathrm{~min}$, $\mathrm{P}=0.001^{*}$ ) were significantly less in clonidine group compared to placebo. The quality of surgical field was better in clonidine group than placebo at all times. No cases of severe bradycardia or clinically significant hypotension were observed in clonidine group. Conclusion: Premedication with intravenous clonidine $3 \mu \mathrm{g} / \mathrm{kg}$ found clinically safe \& effective drug in controlling blood loss and improves quality of surgical field in posterior lumbar fusion surgeries as a sole agent.
\end{abstract}

Key words: Clonidine, Bleeding severity score, Posterior lumbar fusion surgery

\section{Introduction}

Spine surgeries are significantly associated with major blood loss. The amount of blood loss in spine surgeries can be reduced by different strategies like blood conservation methods (preoperative autologous blood donation), muscle paralysis and proper positioning of the patient to reduce intra-abdominal pressure, infiltration of paraspinal tissues with vasopressors, use of antifibrinolytic agents and deliberate controlled hypotensive anaesthesia [1,2].

Controlled hypotension is the simple and best possible way to obtain bloodless surgical field by reducing intraoperative bleeding. To achieve controlled hypotension various drugs have been studied including vasodilators (sodium nitroprusside, nitroglycerin),

Manuscript received: $07^{\text {th }}$ Feb 2016

Reviewed: $16^{\text {th }}$ Feb 2016

Author Corrected: 26 $6^{\text {th }}$ Feb 2016

Accepted for Publication: 04 ${ }^{\text {th }}$ March 2016

International Journal of Medical Research and Review ganglion-blocking agents, beta blockers (esmolol), calcium channel blockers (nicardipine, nimodipine), alpha-2 agonists (clonidine, dexmedetomidine), volatile agents, and magnesium sulphate $[3,4]$. In recent past the drug clonidine has been widely used in anesthesia as anesthetic adjunct to prevent intubation stress response, sedation, analgesic adjuvant to opioids and to produce hypotensive anesthesia with inhalational agents [5].

The aim of this study is to evaluate the efficacy of intravenous clonidine administered preoperatively as a sole agent for controlled hypotension, to determine the amount of blood loss, quality of surgical field, decrease in the duration of surgery and decrease the need for blood transfusion in adult patients undergoing single level posterior lumbar spine fusion surgery.

\section{Methods and Materials}

Available online at: www.ijmrr.in 361 | P a g e 
This randomized double blind placebo controlled clinical trial was conducted in 60 patients aged between 20 and 60 years classified under American Society of Anesthesiologists (ASA) physical status I-II who were scheduled for posterior lumbar spine fusion surgery for degenerative spine disease in our institute during the period of 2012 to 2013 . We excluded patients with cardiac disease (like hypertension, arrhythmia, ischemic heart disease and valve lesions), preexisting coagulation defects, liver disorders, medical renal disease, diabetes mellitus, neuromuscular disorder, and seizure disorder; patients receiving $B$ - blockers, calcium channel blockers, digoxin, anticoagulants or antiplatelets, tricyclic antidepressants, asthmatic patients, patients on long-standing corticosteroids and known hypersensitivity to clonidine.

After obtaining ethical committee approval from our institution and written informed consent from selected patients, they were allocated into two groups by simple randomization using sequentially numbered, opaque sealed envelopes. Group $1(\mathrm{n}=30)$ : received clonidine 3 $\mu \mathrm{g} / \mathrm{kg}$ (diluted with $0.9 \%$ Normal Saline) $20 \mathrm{ml}$ by syringe pump infusion over 15 minutes before surgery and Group $2(\mathrm{n}=30)$ : received placebo $0.9 \%$ Normal Saline (NS) $20 \mathrm{ml}$ same as treatment group.

On arrival to the operating room, the study drug either clonidine or $0.9 \% \mathrm{NS}$ (placebo) infusion started after premedication with $0.03 \mathrm{mg} / \mathrm{kg}$ midazolam. At the same time all the patients were received $7 \mathrm{ml} / \mathrm{kg}$ of ringer's solution by another intravenous line and were monitored for heart rate (HR) and mean arterial pressure (MAP) [invasive and noninvasive], electrocardiography, oxygen saturation (SPO2), temperature and urine output. Immediately after completion of study drug infusion, anesthesia was induced with fentanyl $2 \mu \mathrm{g} / \mathrm{kg} \&$ propofol $3 \mathrm{mg} / \mathrm{kg}$ intravenously. $100 \%$ oxygen was administered by mask, atracurium $0.5 \mathrm{mg} / \mathrm{kg}$ was used to facilitate intubation and the trachea was intubated after 3-5 minutes. All patients were mechanically ventilated with a tidal volume of $7-10 \mathrm{ml} / \mathrm{kg}$, inspiratory/expiratory ratio of $1: 2$, and a respiratory rate adjusted to maintain end-tidal carbon dioxide (ETCO2) concentration of $30-35 \mathrm{mmHg}$ (12-14 breaths/min). General anesthesia was maintained with $1.5 \%$ sevoflurane in a mixture of $\mathrm{O} 2 / \mathrm{N} 2 \mathrm{O}(50 \% / 50 \%)$ and by intermittent injection of fentanyl $0.5 \mu \mathrm{g} / \mathrm{kg}$ and atracurium $0.2 \mathrm{mg} / \mathrm{kg}$ every 30 minutes. Ringer lactate given as maintenance fluid and normal saline for deficits and losses. All patients were placed prone with a chest and pelvic rolls, leaving the abdomen hanging free. All patients were positioned and operated by the same surgery team.

Vital parameters were monitored by same system in all patients. The time duration of surgery, estimated amount of blood loss, surgical area bleeding score, and any blood transfusion were recorded.

If any bradycardia $<50$ beats/minutes was treated by $0.5 \mathrm{mg}$ atropine and the same may be repeated when necessary. In case of any decrease in MAP less than 50 $\mathrm{mmHg}$, concentration of inhalational anesthetic stopped and $3 \mathrm{mg}$ of ephedrine was given as incremental doses if needed and the patient was excluded from the study.

Intraoperative blood loss was estimated by calculating blood collection at suction bottle and weighing blood soaked sponges, surgical drapes, and gowns, which was weighed in dry preoperatively to find the difference.

The quality of surgical field assessed every 30 minutes using 5 point surgical area bleeding score given by Dolman et al $[6,7]$. The surgical area bleeding score was obtained from same surgical team who performed surgery in all patients.

$1=$ Minimal bleeding, not a surgical nuisance

$2=$ Mild bleeding, but does not affect dissection

$3=$ Moderate bleeding, slightly compromises dissection

4=Severe bleeding, significantly compromises dissection

5=Massive bleeding, prevent dissection.

Blood transfusion was determined when estimated blood loss reaches allowable blood loss, the calculation based on preoperative hematocrit (Hct) with target Hct of $27 \%$.

At the end of the surgery inj. Ondensetron $4 \mathrm{mg}$ given intravenously to prevent postoperative vomiting to all patients and they were extubated after administration of $0.5 \mathrm{mg}$ glycopyrrolate and $2.5 \mathrm{mg}$ neostigmine (1:5) to reverse neuromuscular blockade. Vital parameters observed and patients were shifted to post anesthesia care unit. Inj.diclofinac $75 \mathrm{mg}$ i.v twice a day and inj. paracetamol $1 \mathrm{gm}(100 \mathrm{ml})$ i.v infusion twice a day given alternatively for postoperative pain relief.

Statistical Analysis: Sample size was calculated based on previous study values that mean bleeding in the control group $=749.2 \pm 304.5 \mathrm{~mL}$ and mean bleeding in the clonidine group $=422.3 \pm 139 \mathrm{ml}$ (Anvari et al[14]) 
with the assumption that clonidine reduces $20 \%$ of blood loss, arrived a sample size of 12 in each group, for $80 \%$ power and $5 \%$ level of significance. For the consistency of results 30 patients were studied in each group.

Data were analyzed using SPSS version 17. Results were presented as mean $\pm(\mathrm{SD})$, number, and percentage.
Comparison of demographic data, preoperative vital parameters, Hct, estimated blood volume, duration of surgery and amount of blood loss between groups were done by Student's $t$ test. Analysis of variance was used to analyze hemodynamic variables at different time points. Mann- Whitney $U$ test was used to compare the quality of surgical field. $P<0.05$ was considered significant.

\section{Results}

Sixty patients undergoing posterior lumbar spine fusion were divided equally to either the clonidine group ( $\mathrm{n}=30$ ) or the placebo group $(n=30)$. There was no statistically significant difference between the two groups with regard to demographic characters or ASA physical status. There were no statistically significant differences in basal heart rate (HR), mean arterial pressure (MAP) and hematocrit (Hct) between the two groups.[Table 1]

Table 1: Demographic and clinical characters - comparison

\begin{tabular}{|l|l|l|}
\hline Characters & Group 1 & Group 2 \\
\hline $\mathrm{AGE}(\mathrm{Yr})^{\dagger}$ & 44.27 & 44.4 \\
\hline $\mathrm{Sex}(\mathrm{F} \backslash \mathrm{M})^{\ddagger}$ & $20 \backslash 10$ & $18 \backslash 12$ \\
\hline $\mathrm{ASA}(\mathrm{I} \backslash \mathrm{II})^{\ddagger}$ & $21 \backslash 9$ & $23 \backslash 7$ \\
\hline $\mathrm{WT}(\mathrm{Kg})^{\dagger}$ & 66.33 & 66.23 \\
\hline $\mathrm{HT}(\mathrm{Cm})^{\dagger}$ & 161.73 & 163.2 \\
\hline PREOP HR(Mt) & 75.53 & 74.83 \\
\hline PREOP MAP(Mmhg) ${ }^{\dagger}$ & 89.3 & 87.53 \\
\hline Hematocrit(\%) ${ }^{\dagger}$ & 34.13 & 34.23 \\
\hline
\end{tabular}

Values as $\dagger$-mean, $\ddagger$-number

The heart rate was comparatively less in Group 1 than in Group 2 during intraoperative period, but not able to find any statistical significance. [Figure 1]

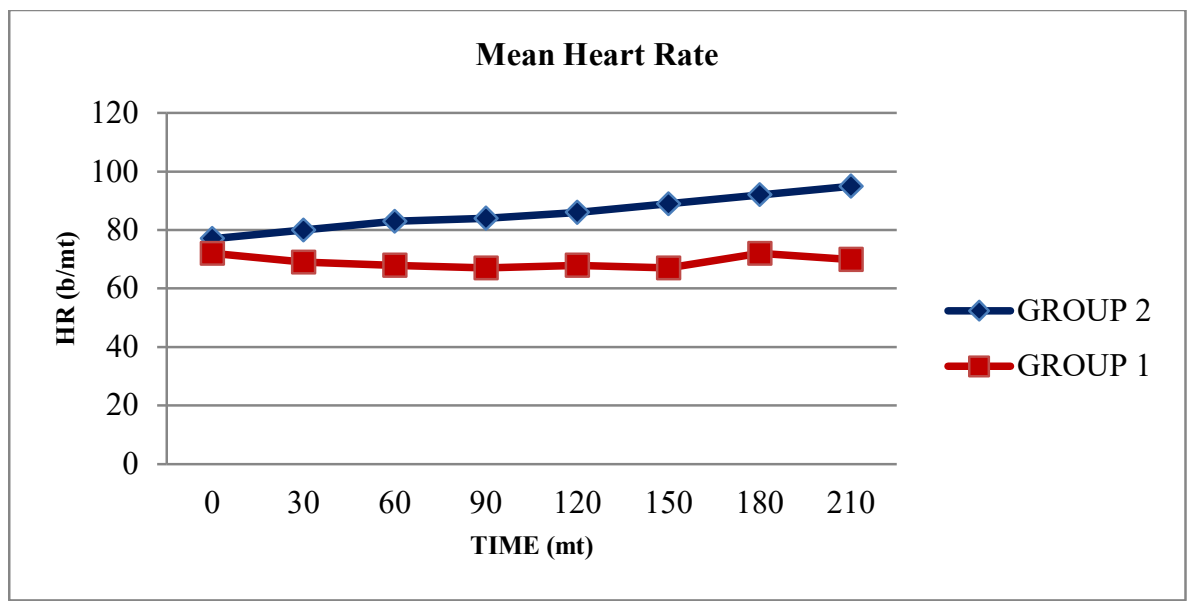

Figure 1: Mean Heart Rate at various time measurements during surgery

Though there was no significance, the MAP was comparatively low in clonidine group than placebo after induction and during intra operative period as well.[Figure 2] After recovery, in the immediate postoperative heart rate and mean blood pressure (MAP) remained significantly (P value $0.001^{*}$ ) less in clonidine group than placebo.[Table 2] 


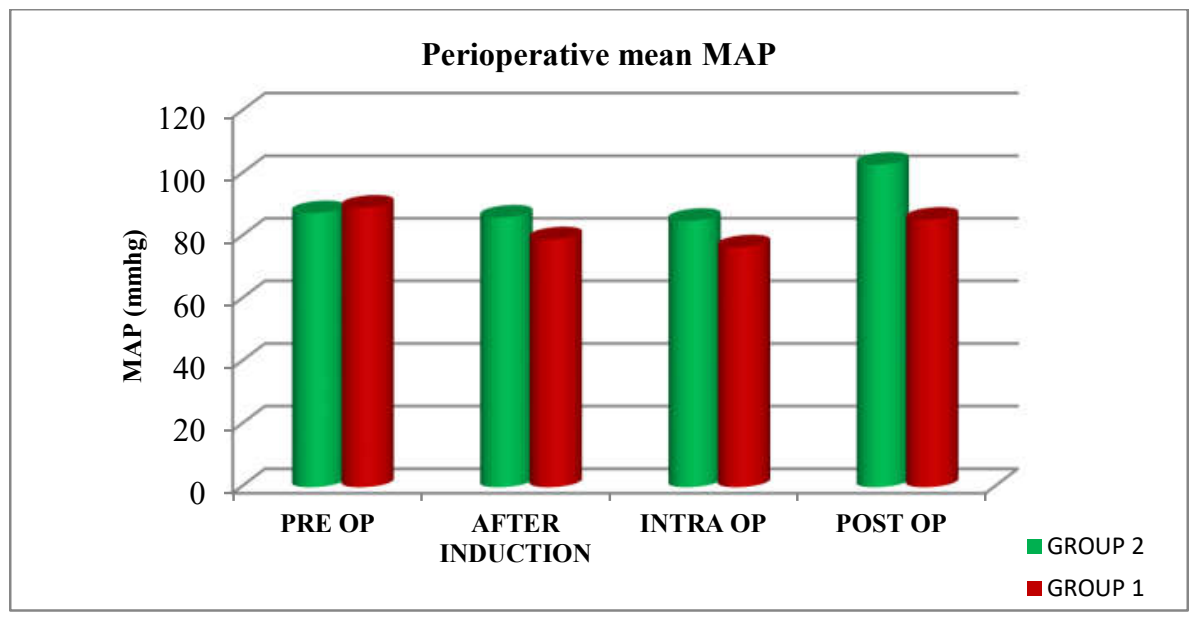

Figure 2 Perioperative mean MAP

Table 2: Heart rate and blood pressure after recovery - comparison

\begin{tabular}{|l|l|l|l|}
\hline & Group 1 & Group 2 & P Value \\
\hline Postop.HR(mt) & $69.73 \pm 11.27$ & $101.07 \pm 7.54$ & $0.001^{*}$ \\
\hline Postop.MAP(mmHg) & $85.43 \pm 6.51$ & $103.03 \pm 4.08$ & $0.001^{*}$ \\
\hline
\end{tabular}

$* \mathrm{P}<0.05$ considered statistically significant Values as mean \pm Standard deviation

The quality of surgical bleeding was assessed every thirty minutes with a five point bleeding score. The quality of surgical field was better in clonidine than placebo in all times of measurements and it was statistically significant at 150 minutes $\left(\mathrm{P}=0.003^{*}\right)$.Number of patients in the clonidine group with surgical area bleeding score of 3 and 4 (bleeding compromises dissection) was less compare to placebo group. [Figure 3] There was no need for nitroglycerin as a rescue hypotensive agent to maintain controlled hypotension in either group.

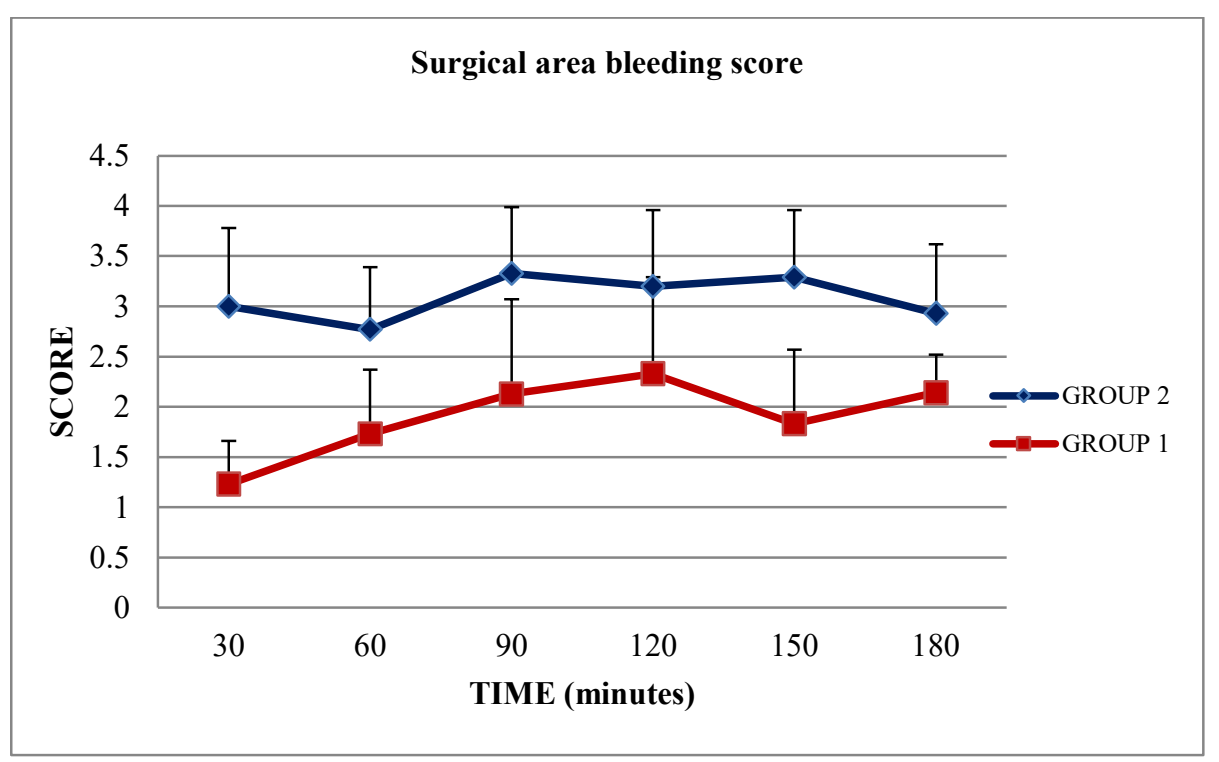

Figure 3: Surgical area bleeding score (mean + SD)

The analysis of estimated blood loss shows that clonidine group had significantly less intraoperative blood loss $\left(390.8 \pm 99.99 \mathrm{~mL} ; \mathrm{P}<0.05^{*}\right)$ compared to placebo group $(741.13 \pm 79.90 \mathrm{~mL})$. It shows approximately $47 \%$ reduction of 
blood loss in clonidine group than placebo. The duration of surgery was significantly less in clonidine Group than placebo Group (160.67 \pm 16.91 vs $205.9 \pm 16.72 \mathrm{~min}, \mathrm{P}<0.05^{*}$ ). [Table 3] No of patients received blood transfusion was higher in placebo when compare to clonidine. In placebo group 12 patients received blood transfusion, in that 5 patients were transfused with 2 units of blood. In clonidine group only 3 patients received blood transfusion.

Table 3: Amount of blood loss and duration of surgery - comparison

\begin{tabular}{|l|l|l|l|}
\hline & Group 1 & Group 2 & P Value \\
\hline Blood loss(ml) & $390.8 \pm 99.99$ & $741.13 \pm 79.90$ & $0.001^{*}$ \\
\hline Duration(mt) & $160.67 \pm 16.91$ & $205.9 \pm 16.72$ & $0.001^{*}$ \\
\hline
\end{tabular}

$* \mathrm{P}<0.05$ considered statistically significant Values as mean \pm Standard deviation

In clonidine group, three patients were treated with inj.atropine $0.5 \mathrm{mg}$ for severe bradycardia otherwise intraoperative period was hemodynamically stable in all patients.

\section{Discussion}

Spine surgeries always associated with major blood loss, necessitates blood transfusion[8,9]. Now a days, avoiding blood transfusion even in major surgical procedures become important to decrease perioperative morbidity and mortality caused by transfusion related adverse events (like transfusion reaction, transmission of infection, TRALI [Transfusion Related Acute Lung Injury], risk of immunosuppression and the cost of hospitalization) [10,11]. Blood transfusion can be limited by decreasing intra operative blood loss, also improves quality of surgical field in turn increases surgeon satisfaction, decreases duration of surgery and neurological complications as well.

Controlled hypotension is the widely accepted technique to reduce intraoperative blood loss in spine surgeries[12]. Malcom-smith study found upto 55\% reduction in the blood loss by induced hypotension method [13].

Recently, the centrally acting antihypertensive agent clonidine has gained considerable interest as an adjuvant in anesthesia. Many previous studies compared the effect of oral clonidine to produce blood less surgical field by its hypotensive action [14-16]. But study on intravenous clonidine was few and they analysed the effect of clonidine on reduction of hemodynamic stress response to laryngoscopy, maintaining controlled hypotension, hemodynamic stability intraoperatively, sedation, analgesia and postoperative shivering [17-22].
Previous studies with oral clonidine premedication shows significant reduction in the requirement of blood transfusion by achieving moderate hypotensive anesthesia [14]. In our study, the effect of intravenous clonidine was compared to placebo for bloodless surgical field alongwith sevoflurane and fentanyl combination. All patients were operated at single level spinal segment for degenerative spine disorders by the same surgical team, and prone positioning done in the same way by the same team. There was no significant difference in weight $\&$ height between the two groups. This way, the other factors (1. Position based increased abdominal pressure causing venous congestion at surgical area. 2. No of segments, 3. Weight, 4. Pathology of disease) which affects surgical area bleeding was minimized.

The MAP was comparatively low in clonidine group than placebo after induction and during intra operative $\&$ immediate post-operative period as well. Also, mean intraoperative estimated blood loss \& duration of surgery were significantly less in the clonidine group than control group. Around 47\% reduction in estimated blood loss was achieved with clonidine compare to placebo.

In our study even with moderate hypotension which is statistically not significant, we found significant amount of reduction in estimated blood loss and the better quality of surgical field with clonidine compare to placebo. The quality of surgical field with bleeding score $3 \& 4$ were less with clonidine compare to 
placebo. This well correlated with the findings of Anvari et al[14] and Jabalameli et al[16] studies.

Kulka et al[17], study on hemodynamic stability with various doses of intravenous clonidine found $4 \mu \mathrm{g} / \mathrm{kg}$ is optimal dose to get better hemodynamic stability than $2 \mu \mathrm{g} / \mathrm{kg}$. And a higher dose at $6 \mu \mathrm{g} / \mathrm{kg}$ does not have any enhanced effect on catecholamine release or hemodynamic variables.

Altan et al[20] and Ray et al[22] studies found significant incidence of bradycardia and hypotension requires treatment which was not there in our study. Altan et al used intravenous clonidine $3 \mu \mathrm{g} / \mathrm{kg} 15$ minutes before induction followed by $2 \mu \mathrm{g} / \mathrm{kg} / \mathrm{h}$ continuous infusion during surgery. Ray et al administered clonidine $3 \mu \mathrm{g} / \mathrm{kg}$ intravenously 15 minutes before induction and continous infusion with 1 $\mu \mathrm{g} / \mathrm{kg} /$ hour intraoperatively. They observed significant incidences of bradycardia and hypotension in their study. Sahajananda \& Rao [19] and Samantaray et al[21] studied the effect of intravenous clonidine at $3 \mu \mathrm{g} / \mathrm{kg}$ observed no significant events like bradycardia and hypotension requires vasopressor, correlates better with our observation.

\section{Conclusion}

Even with moderate hypotension, clonidine in a dose of $3 \mu \mathrm{g} / \mathrm{kg}$, effectively decreases surgical site bleeding and gives bloodless surgical field. So the present study concludes that intravenous clonidine premedication at $3 \mu \mathrm{g} / \mathrm{kg}$ found clinically safe \& effective in controlling blood loss and improves quality of surgical field and decreases need for blood transfusion in single level posterior lumbar fusion surgeries as a sole hypotensive agent.

\section{Funding: Nil}

Conflict of interest: None.

Permission of IRB: Yes

\section{References}

1. Hu SS. Blood loss in adult spinal surgery. Eur Spine J. 2004 Oct;13 Suppl 1:S3-5. Epub 2004 Jun 10.

2. Szpalski M, Gunzburg R, Sztern B. An overview of blood-sparing techniques used in spine surgery during the perioperative period. Eur Spine J. 2004 Oct;13 Suppl 1:S18-27. Epub 2004 Jun 15.
3. Dutton RP. Controlled hypotension for spinal surgery. Eur Spine J. 2004 Oct;13 Suppl 1:S66-71. Epub 2004 Jun 9.

4. Degoute CS. Controlled hypotension: a guide to drug choice. Drugs 2007;67(7):1053-76.

5. Singh S, Arora K. Effect of oral clonidine premedication on perioperative haemodynamic response and postoperative analgesic requirement for patients undergoing laproscopic cholecystectomy. Indian J Anaesth. 2011 Jan;55(1):26-30. doi: 10.4103/0019-5049.76583.

6. Dolman RM, Bentley KC, Head TW, English M. The effect of hypotensive anesthesia on blood loss and operative time during Le Fort I osteotomies. J Oral Maxillofac Surg. 2000 Aug;58(8):834-9; discussion 840.

7. Amr YM, Amin SM. Effects of preoperative oral beta blocker versus intraoperative nitroprusside or esmolol on quality of surgical field during tympanoplasty. J Clin Anesth. $2011 \quad$ Nov;23(7):544-8. doi: 10.1016/j.jclinane.2011.02.007.

8. Butler JS, Burke JP, Dolan RT, Fitzpatrick P, O'Byrne JM, McCormack D, Synnott K, Poynton AR. Risk analysis of blood transfusion requirements in emergency and elective spinal surgery. Eur Spine J. 2011 May;20(5):753-8. doi: 10.1007/s00586-0101500-0. Epub 2010 Jun 27.

9. Fosco M, Di Fiore M. Factors predicting blood transfusion in different surgical procedures for degenerative spine disease. Eur Rev Med Pharmacol Sci. 2012 Nov;16(13):1853-8.

10. Zheng F, Cammisa FP Jr, Sandhu HS, Girardi FP, Khan SN. Factors predicting hospital stay, operative time, blood loss, and transfusion in patients undergoing revision posterior lumbar spine decompression, fusion, and segmental instrumentation. Spine (Phila $\mathrm{Pa}$ 1976) 2002;27:818-24.

11. Carlos Marcucci, Caveh Madjdpour and Donat R Spahn. Allogeneic blood transfusions: benefit, risks and clinical indications in countries with a low or high human development index. Br Med Bul 2004;70:15-28. 
12. Paul JE, Ling E, Laonde C, Thabane L.Delibrate hypotension in orthopedic surgery reduces blood loss and transfusion requirements: a meta-analysis of randomized controlled trials. Can J Anaesth. 2007 Oct;54(10):799-810.

13. Malcolm-Smith NA, McMaster MJ. Effect of clonidine premedication on blood loss in spine surgery. Anesth Pain Med.2012 Spring;1(4):252-6. doi: 10.5812/aapm.2197. Epub 2012 Apr 1.

14. Taghipour Anvari Z, Afshar-Fereydouniyan N, Imani F, Sakhaei M, Alijani B, Mohseni M. Effect of clonidine premedication on blood loss in spine surgery. Anesth Pain Med.2012 Spring;1(4):252-6. doi: 10.5812/aapm.2197. Epub 2012 Apr 1.

15. Ebneshahidi A, Mohseni M. Premedication with oral clonidine decreases intraoperative bleeding and provides hemodynamic stability in cesarean surgery section. Anesth Pain. 2011;1(1):30-3.

16. Jabalameli M, Hashemi S, Soltani H, Hashemi S. Oral clonidine premedication decreases intraoperative bleeding in patients undergoing endoscopic sinus surgery. J Res Med Scie. 2005;10(1):25-30.

17. Kulka PJ, Tryba M, Zenz M. Dose-response effects of intravenous clonidine on stress response during induction of anesthesia in coronary artery bypass graft patients. Anesth Analg. 1995 Feb;80(2):263-8.
18. Lee J, Lovell AT, Parry MG, Glaisyer HR, Bromley LM. I.v. clonidine: does it work as a hypotensive agent with inhalation anaesthesia? $\mathrm{Br} \mathrm{J}$ Anaesth. 1999 Apr;82(4):639-40.

19. Sahajananda $\mathrm{H}$ and Rao S. Effects of intravenous clonidine on haemodynamics and on plasma cortisol level during laparoscopic cholecystectomies. Indian $\mathrm{J}$ Anaesth. 2015 Jan;59(1):53-6. doi: 10.4103/00195049.149458 .

20. Altan A, Turgut N, Yildiz F, Türkmen A, Ustün H. Effects of magnesium sulphate and clonidine on propofol consumption, haemodynamics and postoperative recovery. $\mathrm{Br} \mathrm{J}$ Anaesth. 2005 Apr;94(4):438-41. Epub 2005 Jan 14.

21. Samantaray A, Rao MH, Chandra A. The effect on post-operative pain of intravenous clonidine given before induction of anaesthesia. Indian J Anaesth. 2012 Jul;56(4):359-64. doi: 10.4103/0019-5049.100817.

22. Ray M, Bhattacharjee DP, Hajra B, Pal $\mathrm{R}$, Chatterjee N. Effect of clonidine and magnesium sulphate on anaesthetic consumption, haemodynamics and postoperative recovery: A comparative study. Indian J Anaesth. 2010 Mar;54(2):137-41. doi: 10.4103/0019-5049.63659.

\section{How to cite this article?}

Suresh Rajkumar, Senthil M, Ezhilrajan V. The efficacy of intravenous clonidine premedication to reduce surgical area bleeding in posterior lumbar spine fusion surgery. Int J Med Res Rev 2016;4(3):361-367. doi: 10.17511/ijmrr.2016.i03.13 